\title{
Radiosurgery for symptomatic cavernous malformations in the brainstem
}

\author{
Yoshihisa Kida ${ }^{1 *}$ and Toshinori Hasegawa ${ }^{2}$ \\ ${ }^{1}$ Scientific Committee of Japanese Gamma Knife Society, Gamma Knife Center in Okuma Hospital, Nagoya, Japan \\ ${ }^{2}$ Department of Neurosurgery, Komaki City Hospital, Komaki, Japan
}

\begin{abstract}
Purpose: Cavernous malformations are believed to be clinically silent and some are found just incidentally. However, the lesions once become symptomatic with hemorrhage or epilepsy, they are very troublesome because the repeated episodes may happen. Since the majority of symptomatic incidents of the brainstem lesions are hemorrhage, the prompt treatments are required. Microsurgery has a limited indication such as the lesions easy to access and located just beneath the brainstem surface. It is often difficult and risky to undergo surgery, which requires the skills of the microsurgeon to complete these tasks.
\end{abstract}

Methods and cases: Radiosurgery is an alternative to microsurgery, which has been chosen for treating such symptomatic lesions. Because radiosurgery required no special techniques and can be performed by standard radio surgeons with sufficient knowledge. After the brainstem hemorrhage once or twice, radiosurgery was performed with a mean marginal dose of $12.8 \mathrm{~Gy}$. After the radiosurgery, the follow-up studies were performed at the intervals of every 3 to 6 months.

Results: Radiological studies with MRI demonstrated a lesion shrinkage approximately in half of the lesions, and the others showed no obvious change. A few lesions caused hemorrhage showing enlargement of the lesion in the association of clinical signs, even after the treatment.

Hemorrhage rate before and after the treatment was considerably decreased from $30 \% /$ year/case to $5 \% /$ year/case after the treatment.

Conclusion: Radiosurgery with gamma knife reduced the hemorrhage rate significantly and the lesions were smaller in half and the other half showed no remarkable changes. Since the indication for microsurgery is restricted, radiosurgery is the better treatment option for symptomatic CMs in the brainstem. Radiosurgery might be able to change the natural course of this peculiar disease.

Abbreviation: CM: Cavernous malformation; CNS: Central nervous system; HR: Hemorrhage rate; PFS: Progression-free-survival.

\section{Introduction}

Cavernous malformations (CM) are one of the vascular anomalies similar to arteriovenous malformation, venous anomaly and capillary telangiectasia in the central nervous system (CNS). Different from the other three, CMs are a very peculiar disease. The majority of them are usually very silent, however, they become symptomatic all of the sudden in association with repeated hemorrhages and frequent epilepsy attacks. Once becoming symptomatic, they are so troublesome and may develop frequent episodes and neurological deterioration. This is true especially when the brainstem lesions become symptomatic, exclusively with hemorrhage. Motor dysfunction, ataxia, or disturbed ocular movement are the main and popular symptoms of brainstem hemorrhages. Since they may often appear repeatedly, the patients require prompt treatment procedures to stop the bleeding. A waitand-see strategy may be taken into account when the microsurgery is difficult because of the location and the patient's condition. We, Gamma Knife Teams in Japan, have currently treated these symptomatic CMs in the brainstem with gamma knife radiosurgery in the past 30 years. Here in this paper, our treatment results are summarized and consider the strategy of this serious disease.

\section{Cases and methods}

For this retrospective study, cases were collected from nation-wide Gamma Knife Institutes in Japan. There were 139 cases, 85 males and
62 females, whose ages ranged 8 to 73 with a mean of 40.5 years. The location of the lesions was most popular in the pons (94) and followed by midbrain (28) and medulla (12), two were missing. All the lesions became symptomatic by hemorrhage, which occurred once in 60 , twice in 48 and three times or more in 29 cases. So more than half of cases developed hemorrhage twice or more (Table 1).

Radiosurgery with a gamma knife was performed after the Leksell $\mathrm{G}$ frame fixation to the head of the patients. After the imaging studies either MRI or CT, dose planning with GammaPlan (Elekta $A B$ in Stockholm) was performed. For the brainstem CMs, only the core of lesions was incorporated into the target volume, instead, the areas of peripheral T2-low-signal intensity were not included in the target as shown in Figure 1.

Patients were allowed to move within 1-2 hours after radiosurgery and to discharge the next morning. They could return to their daily life very soon.

${ }^{\star}$ Correspondence to: Yoshihisa Kida, Scientific Committee of Japanese Gamma Knife Society, Gamma Knife Center in Okuma Hospital, Nagoya, Japan, E-mail: yoshihisa_kida@mac.com

Key words: brainstem, cavernous malformation, gamma knife, natural course, radiosurgery

Received: November 30, 2019; Accepted: December 11, 2019; Published: December 16, 2019 
Table 1. Characteristics of the 139 cases of brainstem cavernous malformations treated with gamma knife, which were collected from nation-wide Gamma Knife Institute over Japan. More than half cases caused hemorrhage twice or more. More than $60 \%$ of the lesions are located in pons

\begin{tabular}{|c|c|c|}
\hline No & Contents & \\
\hline 1 & Age & $40.5 \pm 15.5$ years $(8-73$ years $)$ \\
\hline 2 & Sex & Male: 85 Female: 62 \\
\hline 3 & Onset & $\begin{array}{c}\text { Once: } 60 \\
\text { Twice or more: } 77 \\
\text { Missing: } 2\end{array}$ \\
\hline 4 & Location & $\begin{array}{c}\text { Pons: } 94 \text { Midbrain: } 28 \\
\text { Medulla: } 12\end{array}$ \\
\hline 5 & Onset to GK & 30.6 months (1-228 months) \\
\hline
\end{tabular}

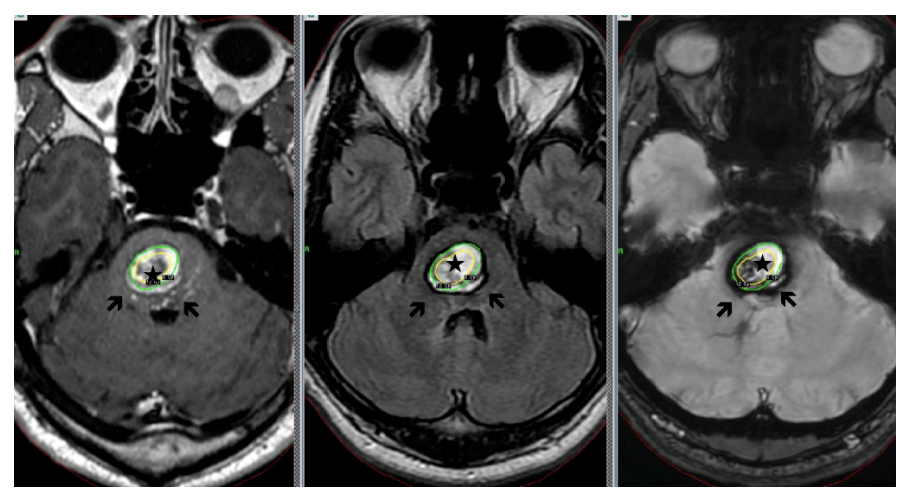

Figure 1. A large cavernous malformation in the pons in association with hemorrhage only the core $\left(^{*}\right)$ in the center was irradiated, contrary hematomas and the areas of T2 lowsignal intensity were not included to the target volume

Follow-up studies and medical check-ups were performed every 3 months after the treatment within a first year and every 6 months thereafter. Statistical analyses are made with student's t-test for the comparison of two paired groups. A P value smaller than 0.05 is considered to be statistically significant.

\section{Results}

\section{Radiosurgery}

The lesions of $\mathrm{CM}$ in the brainstem were estimated to be from 3.1 to $25.7 \mathrm{~mm}$ with a mean diameter of $12.8 \mathrm{~mm}$. They were treated with the mean maximum and marginal doses of $23.1 \mathrm{~Gy}$ and 12.8 Gy respectively (Table 2). Initially, applied marginal doses were even higher and associated with higher complications, and thus the marginal doses were reduced and currently treated with less than 13 Gy at the margin.

\section{Treatment results}

Neurological status were currently improved and recovered from the first incidents by the subsequent absorption of hematomas in the brainstem. On the contrary, the neurological deterioration may occure either by perifocal edema or hemorrhages after the treatment. With the long term follow-up, MRI often showed a remarkable shrinkage of the brainstem lesions in association with neurological recovery (Figure 2). The results of follow-up studies with MRI and/or CT are summarized in Table 3, in which the shrinkage of the lesions were approximately in half and the other half showed no remarkable changes of the lesion size.

\section{Hemorrhage rate (HR)}

There were 214 hemorrhages before gamma knife and 42 hemorrhages after the treatment. The HR, calculated during the first incident to gamma knife treatment, was $30.8 \%$ / case /year. After the radiosurgery, HR decreased to $5.2 \% /$ case/year. Among 42 hemorrhage after the treatment, 20 were within 2 years and 18 were after 2 years.

\section{Hemorrhage-free survival (HFS)}

HFS was shown in the Figure accordingly to each sites of the lesion. The pontine CMs were seemingly worse than others in HFS, but statistically not significant (Figure 3).

\section{Adverse effects}

Most of the complications were related to the rebleeding from the lesions and to radiation injury after the radiosurgery (Table 3). In the early stage of this treatment, couples of radiation injury occurred since they were treated with relatively higher marginal dose above $15 \mathrm{~Gy}$. However, by reducing the marginal doses less than $13 \mathrm{~Gy}$, the complication rate far decreased (Figure 4).

Table 2. Radiosurgery of the brainstem cavernous malformations. Location of the lesions, size and radiation-doses were demonstrated. The mean marginal dose was 12.8 Gy delivered to the lesions with the mean diameter of $12.8 \mathrm{~mm}$

\begin{tabular}{|c|c|c|}
\hline No & & Results \\
\hline 1 & Lesion size & $3.1-25.7 \mathrm{~mm}($ mean $12.8 \mathrm{~mm})$ \\
\hline 2 & Maximum dose & $13.5-32 \mathrm{~Gy}$ (mean $23.1 \mathrm{~Gy})$ \\
\hline 3 & Marginal dose & $8.0-21 \mathrm{~Gy}(12.8 \mathrm{~Gy})$ \\
\hline 4 & Follow-up period & $3.0-215$ months (mean 68 months) \\
\hline
\end{tabular}

Table 3. Results and complications following radiosurgery to symptomatic cavernous malformations in the brainstem. A half of the lesions showed a shrinkage, and the other half demonstrated no remarkable change. The hemorrhage rate decreased from $30.8 \%$ to $5.2 \%$ case/year after the treatment. After the treatment, some cases showed further hemorrhages

\begin{tabular}{|c|c|c|}
\hline No & Factors & Contents \\
\hline 1 & Lesion Control & CR (3) PR (51) MR (12) NC (64) \\
PG (10)
\end{tabular}

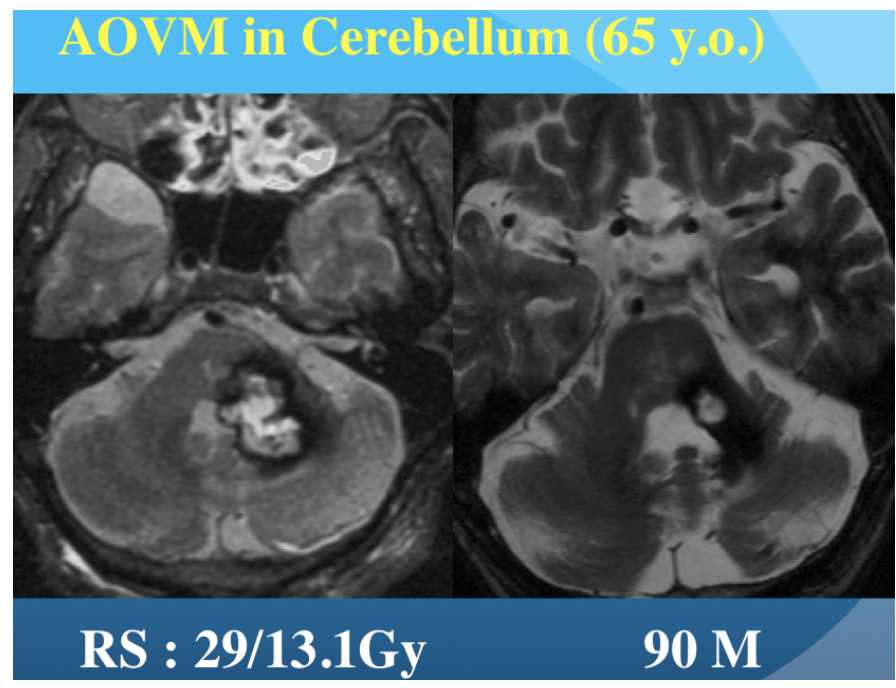

Figure 2. Four times of consecutive hemorrhages by the cavernous malformation. subsequently after the treatment, the lesion became much smaller in size, and showed no further bleeding in the next 20 years 


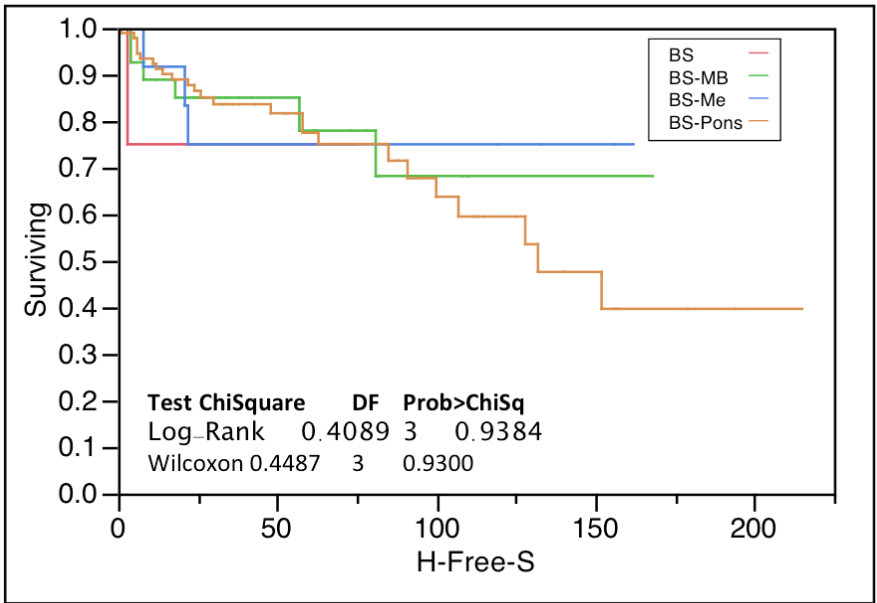

Figure 3. Hemorrhage-Free-Survival after radiosurgery. The lesions in pons demonstrated a worse result of PFS, however no significant differences were found during early 100 months

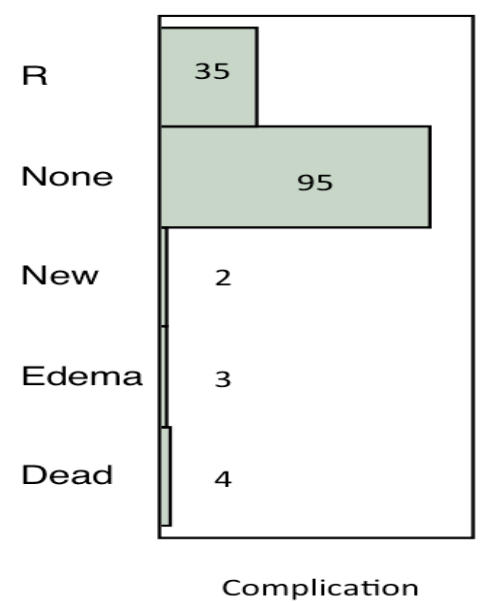

Figure 4. Complications after the radiosurgery hemorrhages were most popular even after the treatment. Perifocal edema and de novo lesions were found rarely

\section{Discussion}

Clinical aspects of cavernous malformation and the natural history

Cavernous malformations in central nervous system are peculiar disease. They are clinically very silent and often found incidentally [13]. When and why they become symptomatic, is not fully understood so far $[4,5]$. Although they are considered to be congenital, they may appear all of sudden sometimes, especially during or after radiation therapy. In fact, we rarely find such brand-new lesions during the follow up studies [6,7]. Therefore the calculation of HR is not so simple. Nevertheless a majority of CMs have been supposed to develop just after birth.

The second thing even more peculiar for CM is the hemorrhage rate. Hemorrhage rates have to be considered after birth or after the first incident. Of course, in calculation of the latter, the first hemorrhages were currently omitted. Tremendous increase of hemorrhage were recorded after the first hemorrhage or incident [4]. From my personal experience, HR jumped up nearly 10 times more after the first hemorrhage, and 20 times more after the second hemorrhage. This is the real reason why symptomatic CM should be treated sooner the better. Since the hemorrhage in the brainstem are apparently more serious, treatment have to be considered as sooner as possible.

\section{Treatment choice}

If the CMs in the brainstem are always silent and clinically stable, a watch-and-see strategy may be possible even for symptomatic lesions. However, the natural history of symptomatic CMs conversely tells us the danger to do so, because symptomatic CMs may cause frequent bleeding after the first incident. This is especially true for brainstem lesions almost all the incidents may associate hemorrhage. Microsurgery with total resection of the lesion can control the subsequent hemorrhages. However, if the lesions are subtotal or partially removed, hemorrhages may occur not infrequently from the remnant of CMs [8-11].

\section{How and why radiosurgery works for hemorrhage control}

There has been a big discussion on the issue to use radiosurgery to intracranial CMs $[12,13]$. As demonstrated in this study, radiosurgery can successfully control the hemorrhages and half of the lesions may shrink. Accordingly, to the reports of many investigators [14-20], the HR were one-tenth after 10 years and the radiological studies showed shrinkage of the lesion more than half cases. These findings indicate that the symptomatic lesions become less symptomatic and less hemorrhagic after radiosurgery. To prove the real effects, histological proof of the obliteration of CMs is necessary. Radiation methods and marginal doses must be discussed since radiation-induced complications were often reported because of high marginal doses. In the present time, most of the lesions in the brainstem are treated less than $15 \mathrm{~Gy}$. Complication rate was far decreased when treated with less than 13 Gy. For the larger lesions of CM, it is important to squeeze the target volume as smaller as possible. To reduce the irradiation to the normal brainstem, fractionated treatment can be considered for large CMs in the brainstem, because it is possible to adjust the dose by fractionation.

\section{Treatment of multiple lesions in the brain and brainstem}

Multiple lesions in the brain and brainstem have been reported by several investigators [21-24]. They have an apparent hereditary and familiar backgrounds and so often numerous lesions were identified in a single case. They often involve the brainstem and seem to be serious once becoming symptomatic. In cases of hereditary background, the lesions are diffuse and multiple and considered to be more aggressive. Recently we have encountered such a case with three symptomatic lesions in the brainstem with consecutive hemorrhages. If multiple lesions become hemorrhagic, the lesions should be treated with radiosurgery one by one. It is not adequate to irradiate asymptomatic lesion, however, symptomatic ones should be treated in order to prevent further hemorrhage.

\section{Treatment strategy in the future}

Since the symptomatic CMs in the cortical or subcortical locations, are apparently easy to access and are readily resected. However, the lesions in the brainstems are totally different because the brainstem is the most eloquent site in CNS. Microsurgery is only allowed for skillful microsurgeons. If there remain any residuals, subsequent treatment with radiosurgery may be required since rebleeding may occur subsequently. Brainstem lesions can be treated only by skillful microsurgeons, conversely, the standard radio surgeons can accomplish these tasks without any difficulties. 


\section{Conclusions}

Utilizing the radiosurgery against symptomatic brainstem CMs, the subsequent hemorrhages were far decreased, which have been indicated by the improved PFS as well as the HR. So long as the brainstem CMs are treated less than 13 Gy at the margin, radiationinduced injury rarely happens. In conclusion, radiosurgery could alter the natural course of the symptomatic CMs to a preferable state. Since the microsurgery to the brainstem may be difficult and risky, radiosurgery has to be considered as the first treatment choice for symptomatic CMs in the brainstem.

\section{Acknowledgments}

We are very grateful for the corporations of many Gamma Knife Institute in Japan for collecting the cases and the data.

\section{Disclosures}

The authors report no conflict of interest concerning the cases and methods used in this clinical study or findings specified in this paper.

\section{References}

1. Del Curling O, Kelly DL, Elster AD, Craven TE (1991) An analysis of the natura history of cavernous angiomas. J Neurosurg 75: 702-708. [Crossref]

2. Kupersmith MJ, Kalish H, Epstein F, Berenstein A, Woo H, et al. (2001) Natural history of brainstem cavernous malformations. Neurosurgery 48: 47-53.

3. Robinson JR, Awad IA, Little JR (1991) Natural history of the cavernous angioma. $J$ Neurosurg 75: 709-714. [Crossref]

4. Kondziolka D, Lunsford LD, Kestle JRW (1995) The natural history of cerebral cavernous malformations. J Neurosurg 83: 820-824.

5. Aboukais R, Estrade L, Devos P, Blons S, Lejeune JP, et al. (2016) Gamma knife radiosurgery of brainstem cavernous malformations. Stereotact Funct Neurosurg 94 : 397-403.

6. Winkler EA, Rutledge C, Ward M, Tihan T, Sneed PK, et al. (2018) Radiation-induced cavernous malformation as a late sequelae of stereotacticradiosurgery for epilepsy. Cureus 10: e2308.

7. Mariniello G, De Liso M, Russo C, Del Vecchio W, De Divitiis O, et al. (2019) Radiation-induced brain cavernomas in elderly: review of the literature and a rare case report. Acta Biomed 90: 77-83. [Crossref]

8. Samii M, Eghbal R, Carvalho GA, Matthies C (2001) Surgical management of brainstem cavernomas. J Neurosurg 95: 825-832. [Crossref]
9. Sola RG, Pulido P, Pastor J, Ochoa M, Castedo J (2007) Surgical treatment of symptomatic cavernous malformations of the brainstem. Acta Neurochir 149: 463-470.

10. Wang CW, Liu AL, Zhang J, Sun B, Zhao Y (2003) Surgical management of brainstem cavernous malformations: Report of 137 cases. Surg Neurol 59: 444-454.

11. Abla AA, Lekovic GP, Turner J, de Oliveria JG, Porter R, et al. (2010) Advances in the treatment and outcome of brain stem cavernous malformation surgery: A case series of 300 surgically treated patients. Neurosurgery 25: 1-10.

12. Ding D (2015) Controversies in the management of brainstem cavernous malformations role of stereotactic radiosurgery. Clin Neurol Neurosurg 131: 88-89. [Crossref]

13. Steiner L, Karlsson B, Yen CP, Torner JC, Lindquist C, et al. (2010) Radiosurgery in cavernous malformations: anatomy of a controversy. J Neurosurg 113: 16-22.

14. Jacobs R, Kano H, Gross BA, Niranjan A, Monaco EA, et al. (2018) Definition longterm clinical outcomes and risks of stereotactic radiosurgery for brainstem cavernous malformations. World Neurosurg 18: S1878-8750.

15. Kida Y (2009) Radiosurgery for cavernous malformations in basal ganglia, thalamus and brainstem. Prog Neuro Surg 22: 31-37. [Crossref]

16. Kondziolka D, Lunsford D, Flickinger JC, Kestle JRW (1995) Reduction of hemorrhage risk after stereotactic radiosurgery for cavernous malformations. $J$ Neurosurg 83: 825831

17. Lee CC, Pan DHC, Chung WY, Liu KD, Yang HC, et al. (2012) Brainstem cavernous malformations: the role of Gamma Knife surgery. J Neurosurg 117: 164-169.

18. Liu HB, Wang Y, Yang S, Gong FL, Xu YY, et al. (2016) Gamma knife radiosurgery for brainstem cavernous malformations. Clin Neurol Neurosurg 151: 55-60. [Crossref]

19. Lu XY, Sun H, Xu JG, Li QY (2014) Stereotactic radiosurgery of brainstem cavernous malformations; a systematic review and metaanalysis. J Neurosurg 120: 982-987.

20. Park K, Kim JW, Chung HT, Paek SH, Kim DG (2018) Long-term outcome of gamma knife radiosurgery for symptomatic brainstem cavernous malformation. World Neurosurg 116: e1054-e1059.

21. Tsutsumi S, Ogino I, Miyajima M, Arai H, Ito M, et al. (2016) Cerebral cavernous malformations with diffuse manifestation: A benign entity? J Neurol Sci 15: 335-341.

22. Belousova OB, Bulygina ES, Okishev DN, Prohorchuk EB, Tsygankova SV, et al (2017) Gene mutations in patients with hereditary cavernous malformations. Zh Neurol Psikhiatr Im S S Korsakova 117: 66-72. [Crossref]

23. Graeni C, Stepper F, Sturzenegger M, Merlo A, Verlaan DJ, et al. (2010) Inherited cavernous malformations of the central nervous system: clinical and genetic features in 19 Swiss families. Neurosurg Rev 33: 47-51

24. Woodall MN, McGettigan M, Figueroa R, Gossage JR, Alleyne CH Jr (2014) Cerebral vascular malformations in hereditary hemorrhagic telangiectasia. $J$ Neurosurg 120: 87 92. [Crossref]

Copyright: (C2019 Kida Y. This is an open-access article distributed under the terms of the Creative Commons Attribution License, which permits unrestricted use, distribution, and reproduction in any medium, provided the original author and source are credited. 